\title{
Performance and Dissemination of Multicut Fodder Crops in Ramanagara District, Karnataka State, India
}

\author{
S. Kamala Bai", K.H. Nagaraj, Syed Mazhar Ali, S.C. Ranganath and B.T. Rayudu \\ KVK, Ramanagara, Karnataka, India \\ *Corresponding author
}

A B S T R A C T

Fodder crops play a vital role in agriculture since continuous supply of nutritious green fodder in sufficient quantity is basic requirement for livestock to cater milk production and also to maintain the health of the livestock. The availability of good quality green fodder is far less than the requirement in Ramanagara district of Karnataka state. The production of fodder in Ramanagara district accounts to $50 \%$ deficit, resulting in underfed and poorly maintained livestock. Further the cattle are not fed according to their age and the weight.

\section{Keywords}

Multicut Fodder, Palatability.

\section{Article Info}

Accepted: 29 September 2017 Available Online: 10 October 2017
The present situation calls for the adoption of improved production technology in fodder crops to obtain maximum biomass per unit area in order to meet the demand. Farmers are in need of highly palatable multicut green fodder that yields throughout the year. Farmers also lack knowledge about the availability of high yielding multicut fodder crop. In the milieu, KVK Ramanagara conducted an On-farm testing on "Performance of Multicut Fodder in Ramanagara District" at Hombalammanapete of Magadi Taluk in five farmers' field. In this study three high yielding multicut fodder crops namely CO-3, COFS-29 and DHN-6 were compared with NB-21 fodder grown locally. Improved cultivation practices of fodder were adopted in the trial under the supervision of KVK Scientist. After every cut growth, yield and quality parameters were recorded such as stem length $(\mathrm{cm})$, Number of tillers per hill, leaf length $(\mathrm{cm})$, Leaf width $(\mathrm{cm})$, Number of leaves per hill, stem girth (cm) and palatability (\%) was recorded at every harvest. Observation recorded on the parameters cumulatively confirmed that DHN-6 multicut fodder recorded highest yield (220t/ ha/ year) followed by COFS-29 (160t/ ha/ year) and Co-3 (160t/ha/year) when compared to locally grown NB- 21 (120t/ ha/ year). Highest palatability (93\%) was recorded in COFS-29 followed by DHN-6 which was $92 \%$.

\section{Introduction}

Ramanagara district is predominantly a dry farming district which lies in geographic position at North Latitude Between $12^{\circ} 33^{\prime}$ to $12^{\circ} 58^{\prime}$ East Longitude Between $77^{\circ} 13^{\prime}$ to $77^{\circ} 25^{\prime}$ under Agro Climatic Zone V. The total geographical area is 3.55 lakh hectares and area under cultivation is 1.69 lakh hectares. The districts support 266192 heads of livestock population. The total area under agriculture land holder is 202566 hectares, among which small and marginal farmers constitute about 66.04 percent of total land holders. There are 271448 number of farm families, among which small and marginal farm families are 92.33 percent of the total farm families followed by small medium $(20.95 \%)$, medium $(11.04 \%)$ and large land holders $(1.15 \%)$. 
Agriculture and animal husbandry is interwoven with the intricate fabric of the district in all walks of life in cultural, religious and economic way as mixed farming. Livestock rearing forms an integral part of living and plays dual role as draught power and source of income for subsistence farms through milk production. The condition of the majority of the animals is deplorably poor, both due to under feeding and malnutrition which is primarily ascribed to fluctuating supply of poor quality of green fodder throughout the year.

Fodder cultivation in the district is cultivated sparsely and in unorganized way. The fodder varieties cultivated are of low yielding coupled with low palatability, more pubescence and difficult to harvest. The opportunity to increase the area under fodder cultivation is impossible due to population density and further most of the farmers come under small and marginal holders with small size of holdings coupled with fragmentation of holdings. Thus, considering the above factors the only way to bridge the gap between the fodder productions and to meet the demand of the green fodder throughout the year is to cultivate multicut fodder varieties to supply quality green fodder throughout the year.

There are many multicut high yielding varieties of fodder available, but no location specific research information on growth, yield and quality attributes and views from the farmers on multicut fodder varieties are available. Therefore, the present exercise was specifically planned through on farm testing (OFT) to assess the "Performance of Multicut fodder crops in Ramanagara district" and to explore their assessment in future prospects. With this background under location specific approach in farmers field a study was undertaken at Hombalmpet, Magadi Taluk, Ramanagara district during the year 2012-13 with the following objectives.
To assess the performance of multicut fodder varieties.

To analyze the attributes of multicut fodder varieties

To understand the farmers opinion about the performance of multi cut fodder.

Impact analysis on production and upscaling of the fodder varieties.

\section{Materials and Methods}

On Farm Testing on Performance of Multicut Fodder Crops" was conducted at Hombalampet in Magadi taluk of Ramanagara district. The experiment was laid out in Randomized Block design with four treatment replicated five times in five farmer's field. The treatments include multicut Napier grasses T1- Check (NB-21), T2- Co-3, T3Sorghum fodder (COFS-29) and T4- DHN-6.

Napier grasses were planted using both rooted slips and stem cuttings (slips). The cuttings were planted at a depth of 3 to $5 \mathrm{~cm}$ on one side of the ridge at spacing of $90 \times 60 \mathrm{~cm}$. COFS-29 fodder seeds @ $12.5 \mathrm{~kg} / \mathrm{ha}$ were sown at spacing of $90 \times 60 \mathrm{~cm}$ at a depth of $2.5 \mathrm{~cm}$. Recommended dose of fertilizer viz., 37.5:62.5:25 kg NPK/ha for Napier grasses and 87.5:50:37.5 kg NPK/ha for COFS-29 was applied. At the time of sowing $25 \%$ nitrogen and entire dose of phosphorus and potassium was applied.

Remaining dose of nitrogen is equally split based on the number of cuts the fodder is harvested. The field was irrigated on 3rd day after planting and as and when required thereafter especially during summer. First harvest was done 55-60 days after planting and subsequent harvest was made at every 5060 days interval. The number of cuts ranged from 6-8 per year. The multicut fodder normally sustains in the field for 2-3 years for 
which the basal application is repeated once in a year for sustained higher yields.

The growth parameters on stem height $(\mathrm{cm})$, number of tillers per culm, leaf length $(\mathrm{cm})$, leaf width $(\mathrm{cm})$, number of leaves per culm, and stem circumference $(\mathrm{cm})$ and yield of green fodder at every harvest (Seven cuts) was recorded and the same was compiled and average was worked out.

The OFT farmers were interviewed from the pre tested questionnaire for the qualitative and quantitative information on visual characters such as growth of the crop, pubescence, palatability, preference, effect on health of animals by feeding these varieties, yield of the fodder and their acceptance for interventions in the farming systems was collected and analyzed based on the descriptive statistics.

\section{Results and Discussion}

In adoption of any new variety, growth and yield are important criteria to show the performance of given interventions. The observations on Stem height $(\mathrm{cm})$, Number of tillers per culm, Leaf length $(\mathrm{cm})$, Leaf width (cm), Stem diameter $(\mathrm{cm})$, number of slips per culm, and yield was recorded at each harvest and average was worked and presented in Table 1.

\section{To assess the performance of multicut} fodder varieties

In order to assess the performance of multicut fodder varieties, growth characteristics and fodder productivity with existing farm situations was recorded and analysed.

Among the growth parameters, DHN-6 recorded highest stem height $(252 \mathrm{~cm})$, number of tillers per culm (25), leaf width $(5.30 \mathrm{~cm})$, number of leaves per culm (190) and stem circumference $(7.20 \mathrm{~cm})$. While
CO-3 recorded highest leaf length $(123 \mathrm{~cm})$ compared to other fodder varieties. Fodder yield is a function of genetic as well as the environmental factors, which plays a vital role in fodder growth and development and ultimately contributed to fodder yield. Highest cumulative fodder yield (t/ha) was recorded in DHN-6 (220 t/ha/year) followed by COFS-29 (160t/ha/yr). The success of any new demonstration or any new variety results on yield. In this intervention DHN-6 performance was high followed by COFS-29 (Table 1).

\section{To analyze the attributes of multicut fodder varieties}

Farmer's perception about qualitative attributes which could be visualized such as growth, pubescence, palatability, preference and effect on health of animals by feeding the new fodder varieties was collected. For all the above growth parameters, DHN-6 was found to be superior where its growth was very luxuriant, flourishing green with abundant foliage due to more number of leaves on the stem compared to other varieties. The number of leaves per plant plays an important role in manufacturing and supply food material synthesized during photosynthesis. Thus an increase or decrease in number of leaves per plant has a direct effect on the green forage yield of forage crops.

When arriving at quality attributes (Table-2), more pubescence was observed in local check and Co-3 compared to other varieties, thus resulting in less palatability by the livestock and poor acceptance by the farmers as the pubescence causes skin irritation and skin cuts at time of harvesting. During the study, positive quality characters of DHN-6 Napier grass such as good foliage, more preference by the cattle's while feeding resulting in good health of animals was noted by the farmers, followed by COFS-29 compared to other varieties. 
Table.1 Performance of multicut fodder varieties on growth and yield

\begin{tabular}{|l|c|c|c|c|c|c|c|}
\hline $\begin{array}{l}\text { Fodder } \\
\text { varieties }\end{array}$ & $\begin{array}{l}\text { Stem } \\
\text { height(cm) }\end{array}$ & $\begin{array}{l}\text { Number of } \\
\text { tillers/culm }\end{array}$ & $\begin{array}{l}\text { Leaf } \\
\text { length(cm) }\end{array}$ & $\begin{array}{l}\text { Leaf } \\
\text { width(cm) }\end{array}$ & $\begin{array}{l}\text { Number of } \\
\text { leaves/culm }\end{array}$ & $\begin{array}{l}\text { Stem } \\
\text { circumference } \\
\text { (cm) }\end{array}$ & $\begin{array}{l}\text { Green } \\
\text { fodder } \\
\text { yield } \\
\text { (t/ha/yr) }\end{array}$ \\
\hline $\begin{array}{l}\text { T1- Local } \\
\text { Check }\end{array}$ & 204.4 & 23.0 & 112.6 & 4.2 & 135.6 & 5.8 & 85.8 \\
\hline T2- Co-3 & 217.5 & 22.8 & 123.0 & 4.1 & 163.6 & 5.6 & 120.2 \\
\hline T3-COFS-29 & 223.6 & 13.0 & 80.3 & 4.5 & 95.2 & 2.8 & 160.4 \\
\hline T4- DHN-6 & 249.8 & 25.0 & 96.5 & 5.3 & 190.5 & 7.2 & 220.6 \\
\hline$S E m \pm$ & 2.4 & 0.7 & 1.6 & 0.2 & 6.8 & 0.2 & 4.2 \\
\hline$C D(\mathrm{p}=0.05)$ & 7.4 & 2.2 & 5.00 & 0.6 & 21.1 & 0.6 & 13.1 \\
\hline
\end{tabular}

Table.2 Attributes and opinion of the farmers about the performance of different multicut fodder

\begin{tabular}{|l|c|c|c|c|}
\hline \multirow{2}{*}{ Parameters } & \multicolumn{4}{c|}{ Opinion } \\
\cline { 2 - 5 } & Local Check & Co-3 & COFS-29 & DHN-6 \\
\hline Growth & Lush green & Luxuriant & Moderate & $\begin{array}{c}\text { Flourishing green and } \\
\text { abundant foliage }\end{array}$ \\
\hline Pubescence & More & Less & Absent & Absent \\
\hline Palatability & Poor Palatable & Moderately & Moderately & Highly Palatable \\
\hline Preference & Less preferred & Moderately & Moderately & Highly preferred \\
\hline $\begin{array}{l}\text { Effects on health of animal } \\
\text { by feeding these varieties }\end{array}$ & Poor & Good & Good & $\begin{array}{c}\text { Very good and } \\
\text { remarkable }\end{array}$ \\
\hline
\end{tabular}

Table.3 Supportive extension activities carried out by Krishi Vigyan Kendra since inception

\begin{tabular}{|l|c|c|c|c|c|}
\hline \multirow{2}{*}{ KVK Intervention } & \multicolumn{4}{|c|}{ Year } & \multirow{2}{*}{ Total } \\
\cline { 2 - 5 } & $\mathbf{2 0 1 1 - 1 2}$ & $\mathbf{2 0 1 2 - 1 3}$ & $\mathbf{2 0 1 3 - 1 4}$ & $\mathbf{2 0 1 4 - 1 5}$ & \\
\hline FLD (Nos) & 1 & 2 & 1 & 1 & 5 \\
\hline OFT (Nos) & - & - & 1 & 1 & 2 \\
\hline $\begin{array}{l}\text { On-Campus training } \\
\text { programs }\end{array}$ & 1 & 1 & 4 & 4 & 10 \\
\hline $\begin{array}{l}\text { Off-Campus training } \\
\text { programs }\end{array}$ & - & 2 & 6 & 8 & 16 \\
\hline Exposure Visits & - & - & 1 & 1 & 5 \\
\hline Field Visits & 4 & 6 & 8 & 12 & 30 \\
\hline Diagnostic Visits & 1 & 2 & 2 & 3 & 8 \\
\hline Field Days & 1 & 2 & 1 & 1 & 5 \\
\hline Guest Lectures & 5 & 6 & 8 & 12 & 31 \\
\hline Collaborative programs & 1 & - & 1 & 1 & 3 \\
\hline Method Demonstrations & 2 & 4 & 2 & 2 & 10 \\
\hline TV Programs & - & - & - & 1 & 1 \\
\hline Publications & 1 & 2 & 4 & 8 & 15 \\
\hline Farmers visited to KVK & 22 & 30 & 18 & 32 & 102 \\
\hline $\begin{array}{l}\text { Consultancy provided } \\
\text { on fodder cultivation }\end{array}$ & 12 & 20 & 23 & 20 & 75 \\
\hline
\end{tabular}


Table.4 An impact analysis on production and upscaling of fodder crops in Ramangara district

\begin{tabular}{|l|l|}
\hline \multicolumn{1}{|c|}{ Particulars } & Details \\
\hline Capacity Building & 34 \\
\hline No. farmers trained & 786 \\
\hline No. field days & 5 \\
\hline Farmers participated & 120 \\
\hline No. Slips produced (KVK + Farmers) & 255000 \\
\hline No. Farmers to whom slips were sold & 1670 \\
\hline No. of exposure visits conducted & 5 \\
\hline Area covered in dist (ha) & 27.00 \\
\hline Average increase in milk yield / day (lt) & 1.5 to 2.00 \\
\hline Total Income generated by farmer & 85000 \\
\hline Total Income generated at KVK & 375000 \\
\hline
\end{tabular}

To understand the farmers opinion about the performance of multi cut fodder

The success of any demonstration intervention completely depends upon results of the given technology. If an intervention produces positive results then the chances of its adoption remain high or otherwise vice versa. The participating OFT farmers was interview about the intervention of the fodder trials in their farming system.

The famers opined that intervention of the fodder trials on performance of multicut fodder varieties was appreciated and ready to adopt new varieties in their fields.

This reflected more demand and preference of fodder specially DHN-6 for its both qualitative and quantitative parameters (Table-2). The data over all depicted that OFT farmers showed their satisfaction about the performance of the fodder trials.

Impact analysis on production and upscaling of the fodder varieties

Krishi Vigyan Kendra since from inception of the year 2011 to 2015 many extension activities on promotion of fodder crops were carried out (Table-3).The interventions included conducting On Farm Testing (OFT)
(2 nos.) and Front Line Demonstration (FLD) (5 nos.), On campus (10) and off campus (16) training programmes in all the villages where fodder OFT and FLD demonstrations were initiated.

Method demonstration (10 nos.) on preparations and planting of root or stem cuttings were demonstrated.

To strengthen and disseminate the technology, literatures on the fodder crops were published and distributed to the farmers during exhibitions, in parallel TV programme was also telecasted about the improved fodder varieties that are demonstrated and available for sale at KVK.

To create the awareness about the new varieties of fodder a fodder cafeteria has been established which include CO-3, CO-4, COFS-29, Phule Yeshwanth, DHN-6, Stylo, Para grass and BHN-11 at KVK farm.

Further, through guest lecturers (31 nos.) during collaborative programs with line departments and KMF, large scale demonstrations was taken up in the district as a major intervention in fodder production, This resulted in covering an area of 27 ha with average increase in milk yield of 1.5 to 2.0 lt/day (Table 4). 
On farm testing of the fodder under location specific, proved well in the dissemination of skill and knowledge of new fodder varieties. Results indicated that DHN-6 variety was most acceptable by the farmers for its luxurious growth, with high palatability and good effect on health of animals supported with high green foliage throughout the year.

\section{References}

Anonymous, 1999, Economic Survey 199899, Government of Karnataka, Bangalore

Anonymous, 2013, Ramanagara District at Glance, 2013-14, District Statistical officer, Ramanagara

\section{How to cite this article:}

Kamala Bai, S., K.H. Nagaraj, Syed Mazhar Ali, S.C. Ranganath and Rayudu, B.T. 2017. Performance and Dissemination of Multicut Fodder Crops in Ramanagara District, Karnataka State. Int.J.Curr.Microbiol.App.Sci. 6(10): 4918-4923. doi: https://doi.org/10.20546/ijcmas.2017.610.463 